\title{
Erratum to: Rivers as Barriers to Primate Distributions in Africa
}

\author{
A. H. Harcourt • M. A. Wood
}

Published online: 4 September 2012

(C) Springer Science+Business Media, LLC 2012

\section{Erratum to: Int J Primatol (2012) 33:168-183 DOI 10.1007/s10764-011-9558-z}

Please note the following corrections to A.H.Harcourt \& Wood, M.A. "Rivers as barriers to primate distributions in Africa." International Journal of Primatology, 33, 168-183, for which the authors apologise.

\section{Pages 178-9}

The paragraph, "Fourteen species reach, enter, or cross the Dahomey Gap (Fig. 3) ... do not cross the Gap. Eight of the species are not stopped by the Gap or its flanking rivers, the Volta and Ouémé." should read: "Thirteen species reach, ... do not cross the Gap. Seven of the species are not stopped ... the Volta and Ouémé."

In Figure 3, the third box down should have the numeral ' 5 ' in it, not ' 6 '.

The changes do not alter the main conclusion that for three species that stop at the edge of the Gap, we cannot yet say whether it was the aridity of the Gap (the usual explanation) or the river along the edge that was the barrier.

The online version of the original article can be found at http://dx.doi.org/10.1007/s10764-011-9558-z.

A. H. Harcourt $(\bowtie) \cdot$ M. A. Wood

Department of Anthropology, Graduate Group in Ecology, University of California, Davis, CA 95616, USA

e-mail: ahharcourt@ucdavis.edu

Present Address:

M. A. Wood

Department of Wildlife and Fisheries Sciences, Texas A\&M University, College Station, TX 77843, USA 